\title{
Thermochromic Biopolymer Based on Natural Anthocyanidin Dyes
}

\author{
Detlef Lötzsch, Ralf Ruhmann, Arno Seeboth \\ Department of Chromogenic Polymers, Fraunhofer Institute for Applied Polymer Research, Berlin, Germany \\ Email: detlef.loetzsch@iap.fraunhofer.de
}

Received April 15, 2013; revised May 8, 2013; accepted May 15, 2013

Copyright (C) 2013 Detlef Lötzsch et al. This is an open access article distributed under the Creative Commons Attribution License, which permits unrestricted use, distribution, and reproduction in any medium, provided the original work is properly cited.

\begin{abstract}
Recently a novel thermochromic poly(lactic acid) (PLA)-composite material was presented. Depending on temperature the incorporated anthocyanidin dye was found to be present either in its neutral or anionic anhydrobase form. A reversible formation of PLA-dye complexes triggered by conformational changes of the polymer backbone was proposed to explain this thermochromic effect. In order to study the influence of the dye structure on the PLA-dye complex formation and on the thermochromic properties of the PLA-composite material a variation of the anthocyanidin dye structure was investigated. The results indicate that a hydroxyl group in 3'-position of the anthocyanidin dye resulting in the presence of adjacent hydroxyl groups is mandatory for the PLA-anthocyanidin dye complex formation and thus for the occurrence of thermochromism.
\end{abstract}

Keywords: Thermochromism; Biopolymer; Anthocyanidin

\section{Introduction}

Thermochromic polymers can be subclassified into three groups: 1) polymers which are thermochromic themselves [1-6]; 2) polymers which become thermochromic by the incorporation of a thermochromic dopant [7-11]; 3) polymers which become thermochromic by the interaction between the polymer matrix and the incorporated additive system [12-14]. Whereas polymers of the first and the second group are frequently described in literature only a few examples of the third group were reported so far. The thermochromic polymer classes of this group were developed by creating specific function by design strategies. This concept bears a high potential for a purposive development of novel thermochromic polymer materials.

A current example is the development of the first nontoxic thermochromic polymer material [13]. Starting from cyanidin chloride, an anthocyanidin dye, a novel thermochromic polymer-composite was created in which depending on temperature the dye was found to be either present in its wine red colored neutral or in its violet colored anionic anhydrobase form. This composite consists of poly(lactic acid) (PLA), dodecyl gallate, hexadecanoic acid and cyanidin chloride. The structural change of the dye was explained by reversible formation of PLA-dye complexes triggered by conformational changes of the polymer backbone as displayed in Figure 1.

In detail the following mechanism was proposed: in the polymer melt and in the mobile amorphous phase of the glass state the polymer backbone is sufficiently flexible to form multiple H-bonds with the hydroxyl groups of the dye. The detection of the violet colored anionic anhydrobase form indicates PLA-dye complexes. Induced by the presence of solid hexadecanoic acid rich domains the mobile amorphous phase of the glass state transforms into a rigid amorphous phase. This transformation is accompanied by a destabilization of the PLAdye complexes and a change of the dye structure into its wine red colored neutral anhydrobase form occurs.

Although this model provides a phenomenological description of the mechanism the role of the molecular structure of the anthocyanidin dye on the formation of PLA-dye complexes was not clarified in detail.

Anthocyanidins are natural colorants which occur in a wide variety of flowers and fruits $[15,16]$. The general structure of anthocyanidins is displayed in Figure 2.

Up to now, 23 different anthocyanidins were identified. The most common of them are pelargonidin, cyanidin, peonidin, delphinidin, petunidin and malvidin which differ in the substitution pattern of the B-ring including the number of hydroxyl and methoxy groups. Especially the number and position of hydroxyl groups can be expected 
Rigid amorphous phase

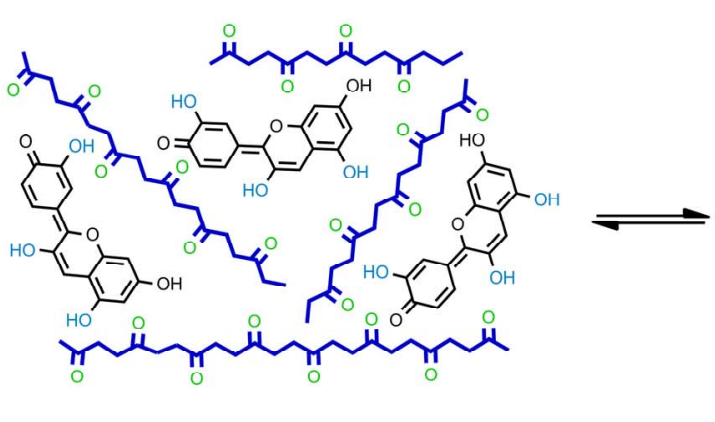

Mobile amorphous phase / polymer melt

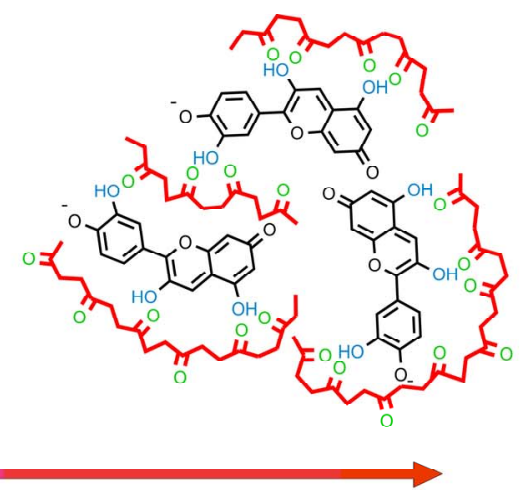

Figure 1. Mechanism of the thermochromic effect.<smiles>[R]c1cc(OC)c2cc([R])c([R])c([R])c2c1</smiles>

Figure 2. General structure of anthocyanidins.

to effect the complex formation between the anthocyanidin dye and PLA. The present work studied this influence.

\section{Experimental}

\subsection{Materials}

Pelargonidin chloride (Phytoplan), delphinidin chloride (Phytoplan), dodecyl gallate (Sigma-Aldrich), hexadecanoic acid (Sigma-Aldrich) and the poly(lactic acid) PLA 4060D (Natureworks) were purchased from commercial suppliers. The PLA 4060D was dried for at least $12 \mathrm{~h}$ at $45^{\circ} \mathrm{C}$ immediately before use. All other materials were used as received.

\subsection{Preparation and Characterization Methods}

PLA-composites were manufactured by using a twin screw extruder ZK 25 T (Dr. Collin GmbH) with corotating screws (diameter $D=25 \mathrm{~mm}$ and length $L=24$ D). The compounding of PLA 4060 with the respective additives was carried out under the following conditions: sample load: $0.5 \mathrm{~kg} \cdot \mathrm{h}^{-1}$, temperature profile: $175^{\circ} \mathrm{C} /$ $185^{\circ} \mathrm{C} / 185^{\circ} \mathrm{C} / 160^{\circ} \mathrm{C} / 135^{\circ} \mathrm{C}$, screw speed: $20 \mathrm{rpm}$.

A laboratory press P200 P/M (Dr. Collin $\mathrm{GmbH}$ ) was used to manufacture flat polymer sheets of the PLAcomposites with a size of $50 \mathrm{~mm} \times 50 \mathrm{~mm} \times 0.5 \mathrm{~mm}$.

The Vis absorption spectra were recorded by using a Jasco V-670 spectrometer. All spectra were measured with a scan speed of $2000 \mathrm{~nm} \cdot \mathrm{min}^{-1}$, a bandwidth of 2 $\mathrm{nm}$ and a data interval of $1 \mathrm{~nm}$. A linear baseline correction was applied to all spectra.

A Perkin Elmer DSC 7 was employed for the differential scanning calorimetric measurements. These measurements were performed at a scanning rate of $5 \mathrm{~K} \cdot \mathrm{min}^{-1}$ on samples whose weights ranged between $5 \mathrm{mg}$ and 20 mg.

\section{Results and Discussion}

Two series of PLA-composites were prepared in analogy to the PLA-cyanidin chloride-composites described in [13]. Series I consists of the matrix polymer PLA and an anthocyanidin dye (a: pelargonidin chloride, b: delphinidin chloride) whereas the composites of series II additionally contain dodecyl gallate and hexadecanoic acid. These additives were successfully used in the PLAcyanidin chloride-composite material to induce thermochromism. The compositions of the investigated PLAcomposites are listed in Table 1.

The molecular structures of the used anthocyanidin dyes differ by only one hydroxyl group each from the structure of cyanidin chloride (Figure 3). A homologous series with one to three hydroxyl groups on the B-ring evolves. The introduction of the hydroxyl groups also leads to the presence of adjacent hydroxyl groups in cyanidin chloride and delphinidin chloride, which is an essential condition for their ability to form chelate-complexes [15-18]. Increasing number of hydroxyl groups and the presence of adjacent hydroxyl groups should also stabilize the formation of PLA-dye complexes [19]. This assumption becomes already obvious by the different colors of the PLA-composites Ia and Ib (see Figure 4). The red color of PLA-composite Ia indicates that pelargonidin chloride is present in its neutral anhydrobase form in PLA and that it forms no PLA-dye complexes. The violet color of PLA-composite $\mathrm{Ib}$ indicates that delphinidin chloride forms PLA-dye complexes in which it is present in its anionic anhydrobase form. 
Table 1. Compositions of the investigated PLA-composites.

\begin{tabular}{cccccc}
\hline $\begin{array}{c}\text { PLA- } \\
\text { composite }\end{array}$ & PLA & $\begin{array}{c}\text { Dodecyl } \\
\text { gallate }\end{array}$ & $\begin{array}{c}\text { Hexadecanoic } \\
\text { acid }\end{array}$ & $\begin{array}{c}\text { Pelargonidin Delphinidin } \\
\text { chloride }\end{array}$ \\
chloride
\end{tabular}

Figure 3. Molecular structures of the investigated anthocyanidin dyes.

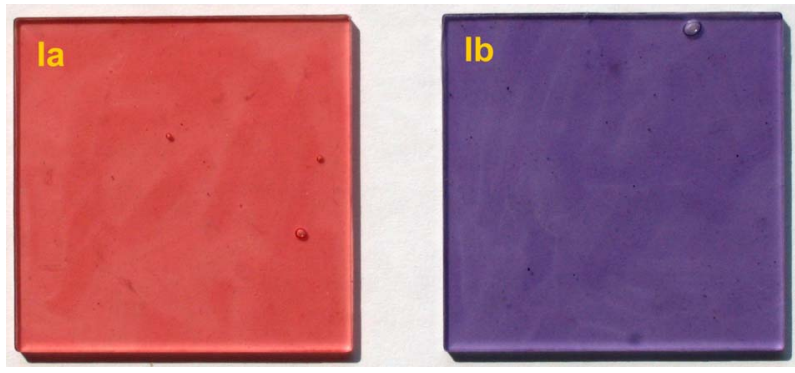

Figure 4. Photo of samples Ia and Ib.

A thermochromic PLA-cyanidin chloride-composite material was obtained by the addition of dodecyl gallate and hexadecanoic acid [13]. The PLA-composites IIa and IIb differ from this thermochromic composite only by the used anthocyanidin dye whereby the molecular concentration of the dye was kept constant.

DSC measurements carried out on IIa and IIb show that the exchange of the dye has no influence on the phase behavior of the PLA-composite materials. Similar to the cyanidin chloride containing PLA-composite material, two transitions were detected for IIa and IIb. As an example the results of the DSC measurements for IIb are displayed in Figure 5. At about $60^{\circ} \mathrm{C}$ which corresponds to the melting temperature of hexadecanoic acid, a peak is observed indicating the presence of separate hexadecanoic acid rich domains. Moreover, at about $45^{\circ} \mathrm{C}$ which corresponds to the glass transition temperature, a step is detected which on aging at room temperature slowly transforms into a peak. Conformational changes of the PLA backbone within the glass state are the origin of this effect leading to a transformation from a mobile into a rigid amorphous phase.

Absorption measurements for IIa at various temperatures ranging from $20^{\circ} \mathrm{C}$ to $70^{\circ} \mathrm{C}$ are shown in Figure 6 . In contrast to the analogous cyanidin chloride containing

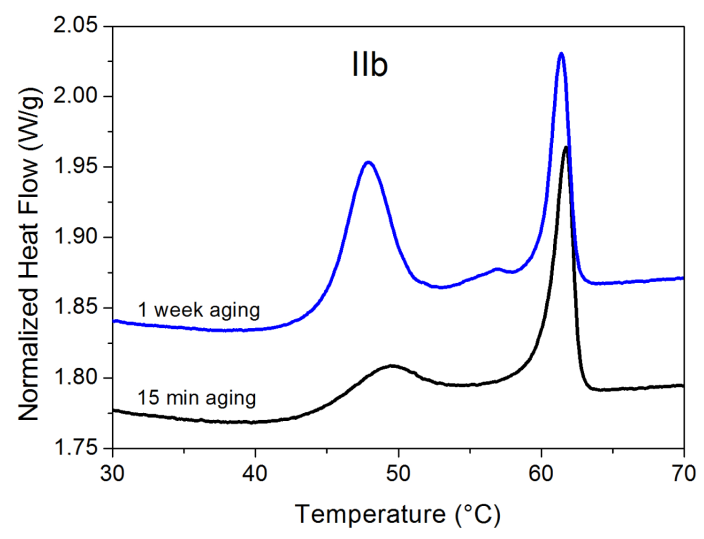

Figure 5. DSC curves of the delphinidin chloride containing PLA-composite IIb after $15 \mathrm{~min}$ and after 1 week of aging at room temperature.

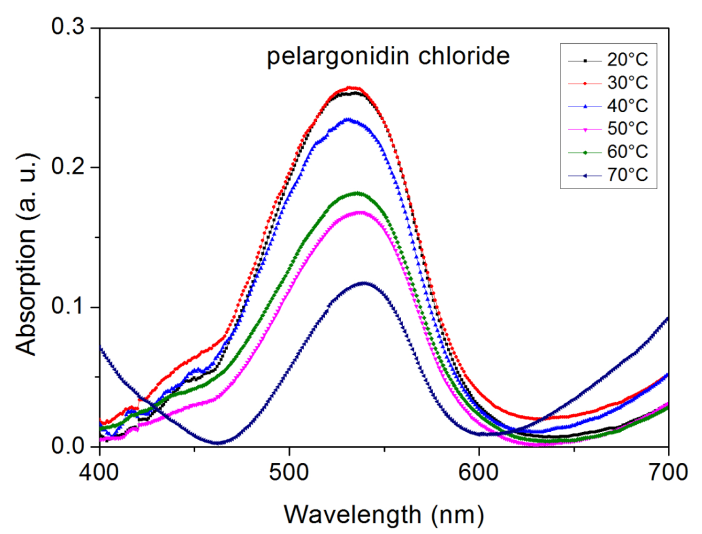

Figure 6. Temperature dependence of the visible absorption of the pelargonidin chloride containing PLA-composite IIa measured on heating (sample thickness $0.5 \mathrm{~mm}$ ).

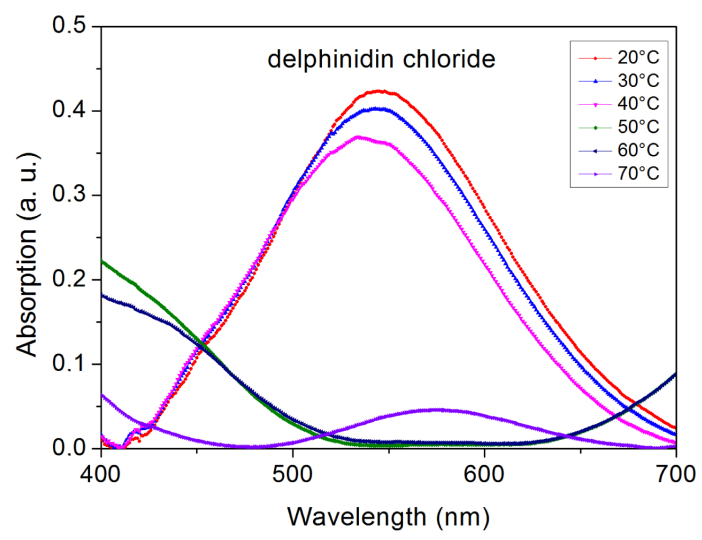

Figure 7. Temperature dependence of the visible absorption of the delphinidin chloride containing PLA-composite IIb measured on heating (sample thickness $0.5 \mathrm{~mm}$ ).

PLA-composite no thermochromic effect is observed. In all states one absorption peak with a maximum of about $530 \mathrm{~nm}$ is detected indicating the presence of the neutral anhydrobase form. Exchanging pelargonidin chloride by delphinidin chloride (IIb) results in a fundamental change 
of the optical properties. As displayed in Figure 7 the PLA-composite now exhibits thermochromic properties. Below the glass transition temperature an absorption peak with a maximum at about $545 \mathrm{~nm}$ is detected. On heating above the glass transition temperature the absorption peak at about $545 \mathrm{~nm}$ vanishes and a new absorption peak at about $575 \mathrm{~nm}$ is observed. This change is caused by a structural rearrangement of the dye from its neutral into its anionic anhydrobase form and indicates formation of PLA-dye complexes above the glass transition temperature.

The results of the colorimetric investigations of the PLA-composites Ia, Ib, IIa and IIb as well as those of the dodecyl gallate solutions of the anthocyanidin dyes are summarized in Table 2. For comparison the respective results for cyanidin chloride are also displayed.

The similarity between cyanidin chloride and delphinidin chloride can be clearly observed. Both dyes exhibit different colors in dodecyl gallate and in PLA (series I), but do not show thermochromism in these matrices. This effect is called solvatochromism [20,21]. Moreover, thermochromism occurs in the PLA-composites (series II) for both dyes. After the rigid amorphous phase is formed, the color of the glass state differs from the color above the glass transition temperature.

In contrast to the dyes with adjacent hydroxyl groups pelargonidin chloride shows neither solvatochromism nor thermochromic effects in the investigated matrices.

In addition to those on the B-ring, all dyes bear three more hydroxyl groups on the benzopyran moiety. Hence the overall number of hydroxyl groups increases only slightly from 4 (pelargonidin chloride), to 5 (cyanidin chloride), to 6 (delphinidin chloride). It is reasonable to expect that not the overall number of hydroxyl groups but the presence of adjacent hydroxyl groups in cyanidin chloride and delphinidin chloride is the reason for the observed solvatochromic and thermochromic effects.

\section{Conclusion}

The influence of the molecular structure of anthocyanidin

Table 2. Wavelengths ( $\mathrm{nm})$ of absorption maxima in the visible range of various anthocyanidin dyes in a) dodecyl gallate, b) PLA and c) PLA-composite.

\begin{tabular}{cccc}
\hline \multirow{2}{*}{ Dye } & \multicolumn{2}{c}{ Wavelengths (nm) of absorption maxima in the matrix } \\
\cline { 2 - 4 } & $\begin{array}{c}\text { Dodecyl } \\
\text { gallate }\end{array}$ & $\begin{array}{c}\text { PLA } \\
\text { (series I) }\end{array}$ & $\begin{array}{c}\text { PLA-composite } \\
\text { (series II) }\end{array}$ \\
\hline $\begin{array}{c}\text { Pelargonidin } \\
\text { chloride }\end{array}$ & 530 & 530 & 530 \\
$\begin{array}{c}\text { Cyanidin } \\
\text { chloride }\end{array}$ & 540 & 560 & $530 / 560$ \\
$\begin{array}{c}\text { Delphinidin } \\
\text { chloride }\end{array}$ & 545 & 575 & $545 / 575$ \\
\hline
\end{tabular}

dyes on their ability to show thermochromism in a tailored PLA-composite material (series II) has been investigated. Only in case of anthocyanidin dyes bearing a hydroxyl group in 3'-position thermochromism has been observed. Obviously, the presence of adjacent hydroxyl groups in the anthocyanidin dye structure is mandatory for the effect.

\section{Acknowledgements}

Financial support by Fraunhofer-Gesellschaft, München (project number 253 138) is gratefully acknowledged.

\section{REFERENCES}

[1] W. Liang and F. E. Karasz, "Solid-State Thermochromic Transition in Poly(2-methoxyphenylene Vinylene)," Polymer, Vol. 34, No. 13, 1993, pp. 2702-2706. doi:10.1016/0032-3861(93)90109-N

[2] M. Leclerc, "Optical and Electrochemical Transducers Based on Functionalized Conjugated Polymers," Advanced Materials, Vol. 11, No. 18, 1999, pp. 1491-1498. doi:10.1002/(SICI)1521-4095(199912)11:18<1491::AIDADMA1491>3.0.CO

[3] A. F. Thünemann, S. Janietz, S. Anlauf and A. Wedel, "Thermochromism of a Liquid Crystalline Dialkoxy Substituted Poly(1,4-phenylene-1,3,4-oxadiazol-2,5-diyl)," Journal of Materials Chemistry, Vol. 10, No. 12, 2000, pp. 2652-2656. doi:10.1039/b005757f

[4] Y. Gu, W. Cao, L. Zhu, D. Chen and M. Jiang, "Polymer Mortar Assisted Self-Assembly of Nanocrystalline Polydiacetylene Bricks Showing Reversible Thermochromism," Macromolecules, Vol. 41, No. 7, 2008, pp. 2299 2303. doi:10.1021/ma800023f

[5] D. J. Ahn, S. Lee and J. M. Kim, "Rational Design of Conjugated Polymer Supramolecules with Tunable Colorimetric Responses," Advanced Functional Materials, Vol. 19, No. 10, 2009, pp. 1483-1496. doi:10.1002/adfm.200801074

[6] L. Yu and S. L. Hsu, "A Spectroscopic Analysis of the Role of Side Chains in Controlling Thermochromic Transitions in Polydiacetylenes," Macromolecules, Vol. 45, No. 1, 2012, pp. 420-429. doi:10.1021/ma201519v

[7] B. L. Lucht, W. B. Euler and O. J. Gregory, "Investigation of the Thermochromic Properties of Polythiophenes Dispersed in Host Polymers," Polymer Preprints, Vol. 43, No. 1, 2002, pp. 59-60.

[8] A. Seeboth, D. Lötzsch, E. Potechius and R. Vetter, "Thermochromic Effects of Leuco Dyes Studied in Polypropylene," Chinese Journal of Polymer Science, Vol. 24, No. 4, 2006, pp. 363-368. doi:10.1142/S0256767906001400

[9] A. Seeboth, A. Klukowska, R. Ruhmann and D. Lötzsch, "Thermochromic Polymer Materials," Chinese Journal of Polymer Science, Vol. 25, No. 2, 2007, pp. 123-135. doi:10.1142/S0256767907001923

[10] M. Rubacha, "Thermochromic Cellulose Fibers," Advances in Polymer Technology, Vol. 18, No. 4, 2007, pp. 
323-328. doi:10.1002/pat.889

[11] W. Ogrodnik, "Use of Color-Changing Pigment to Detect Wire and Cable Hazards," Wire Journal International, Vol. 41, No. 4, 2008, pp. 150-155.

[12] A. Seeboth, J. Kriwanek and R. Vetter, "The First Example of Thermochromism of Dyes Embedded in Transparent Polymer Gel Networks," Journal of Materials Chemistry, Vol. 9, No. 10, 1999, pp. 2277-2278. doi: $10.1039 / \mathrm{a} 906159 \mathrm{~b}$

[13] A. Seeboth, D. Lötzsch and R. Ruhmann, "First Example of a Non-Toxic Thermochromic Polymer MaterialBased on a Novel Mechanism," Journal of Materials Chemistry C, Vol. 1, No. 16, 2013, pp. 2811-2813. doi:10.1039/c3tc30094c

[14] M. G. Baron and M. Elie, "Temperature Sensing Using Reversible Thermochromic Polymeric Films," Sensors and Actuators B, Vol. 90, No. 1-3, 2003, pp. 271-275. doi:10.1016/S0925-4005(03)00045-5

[15] K. Yoshida, M. Mori and T. Kondo, "Blue Flower Color Development by Anthocyanidins: From Chemical Structure to Cell Physiology," Nature Product Reports, Vol. 26, No. 7, 2009, pp. 884-915. doi:10.1039/b800165k

[16] A. Castaneda-Ovando, L. Pacheco-Hernandez, E. PaezHernandez, J. A. Rodriguez and C. A. Galan-Vidal, "Chemical Studies of Anthocyanins: A Review," Food Chem- istry, Vol. 113, No. 4, 2009, pp. 859-871.

[17] T. Goto and T. Kondo, "Structure and Molecular Stacking of Anthocyanins-Flower Color Variations," Angewandte Chemie, Vol. 30, No. 1, 1991, pp. 17-33. doi:10.1002/ange.19911030105

[18] M. Buchweitz, G. Gudi, R. Carle, D. R. Kammerer and H. Schulz, "Systematic Investigations of Anthocyanin-Metal Interactions by Raman Spectroscopy," Journal of Raman Spectroscopy, Vol. 43, No. 12, 2012, pp. 2001-2007. doi:10.1002/jrs.4123

[19] Y. Lin, K.-Y. Zhan, Z.-M. Dong, L.-S. Dong and Y.-S. Li, "Study of Hydrogen-Bonded Blend of Polylactide with Biodegradable Hyperbranched Poly(Ester Amide)," Macromolecules, Vol. 40, No. 17, 2007, pp. 6257-6267. doi:10.1021/ma070989a

[20] P. Bamfield and M. G. Hutchings, "Chromic Phenomena: Technological Applications of Colour Chemistry," 2nd Edition, The Royal Society of Chemistry, Cambridge, 2010.

[21] C. Reichardt, "Solvatochromism, Thermochromism, Piezochromism, Halochromism, and Chiro-Solvatochromism of Pyridinium N-phenoxide Betaine Dyes," Chemical Society Reviews, Vol. 21, No. 3, 1992, pp. 147-153. doi: $10.1039 / \operatorname{cs} 9922100147$ 